\title{
DETERMINATION OF THE DETERMINANTS OF COMPETITIVENESS FOR HVAC-R SECTOR
}

\author{
DOI: $10.17261 /$ Pressacademia.2018.908 \\ PAP- V.7-2018(61)-p.326-329
}

Husniye Ors ${ }^{1}$, Fatih Yumus ${ }^{2}$

${ }^{1}$ Gazi University, Emniyet Mahallesi Muammer Bostancı Cad. No: 4 Besevler, Ankara, Turkey. ohusniye@gmail.com, ORCID: 0000-0002-8319-3340

${ }^{2}$ Central Anatolian Exporters' Association, C.Atuf Kansu Cad. No.120 Cankaya, Ankara, Turkey. fatihyumus@gmail.com, ORCID: 0000-0003-0282-5076

To cite this document

Ors, H., Yumus, F. (2018). Determination of the determinants of competitiveness for HVAC-R Sector. PressAcademia Procedia (PAP), V.7, p.326-329.

Permemant link to this document: http://doi.org/10.17261/Pressacademia.2018.908

Copyright: Published by PressAcademia and limited licenced re-use rights only.

\section{ABSTRACT}

Purpose- Turkish HVAC-R sector has recently increased its production and export value, as well as being considered as having high potential in terms of these two factors. Thanks to the current public policy which is determinative and supports production; it's supposed capital and technology intensive sectors' competitive level to raise up. Nevertheless, it's discussed broadly that it's clear of the 2023 goals to come true, in view of the export progress. As a result of these circumstances, analyzing current competitiveness of sectors has a strategical importance. It has been seen in the literature review that, any study has not been executed which puts forward the dynamics to be used to analyze the competitiveness of Turkish HVAC-R sector. With this study, it's aimed that to be determined the dynamics of competitiveness of HVAC-R sector, which is a capital and technology intensive sector, by taking into consideration its idiosyncratic characteristics.

Methodology- The study is a typical exploratory research with this essence. In the research, deep interview method was used with the sector's experts those had been chosen by judgement sampling. So data has been primary data as well as the other information has been picked up from secondary data resources. For this data gathering, scientific publishments, various chambers', associations', and institutions' reports was compiled.

Findings- With this research, it has been found out what the determinants of competitiveness that can be used in the analysis of competitiveness of HVAC-R sector are.

Conclusion- The findings that were achieved by primary research, has generated a base for the following researchs of competitive anaylsis of HVAC-R sector.

Keywords: Determinants of competitiveness, HVAC-R, competitiveness.

JEL Codes: L64, F17

\section{IKLIMLENDIRME SEKTÖRÜNÜN REKABET GÜCÜNÜN BELIRLEYICILERININ BELIRLENMESi}

\section{ÖZET}

Amaç- Türkiye iklimlendirme sektörü son dönemde üretimini ve ihracatını artıran, diğer taraftan bu iki faktör açısından potansiyeli yüksek olan bir sektör olarak karşımıza çıkmaktadır. Türkiye ekonomisinde son dönemde belirleyici olan ve üretimi destekleyen politikalar ile sermaye ve teknoloji yoğun sektörlerin rekabet gücünün düzeyinin artması beklenmekle birlikte Türkiye ihracatının gelişimi göz önüne alındığında 2023 hedeflerine ulaşmanın gerçekleşebilir olmaktan uzak olduğu tartışılmaktadır. Bu çerçevede sektörlerin mevcut rekabet gücünün analiz edilmesi stratejik bir önem taşımaktadır. Yapılan literatür incelemesinde, Türkiye iklimlendirme sektörünün rekabet gücü analizlerinde kullanılması gereken belirleyicilerin neler olduğunu ortaya koyan bir çalışmanın yürütülmediği görülmektedir. Bu çalışmayla ulaşılan, sermaye ve teknoloji yoğun bir sektör olan iklimlendirme sektörünün, sektörün kendine has özellikleri de göz önüne alınarak, rekabet gücünün belirleyicilerinin belirlenmesidir.

Yöntem- Araştırma bu yönü ile keşfedici bir nitelik taşımaktadır. Araştırmada yargısal örnekleme yapılarak sektörde konu ile ilgili uzmanlarla derin mülakat yöntemi kullanılarak birincil veri ile beraber ikincil kaynaklarından veri toplanmıştır. Bu amaca ulaşmak için bilimsel yayınlar ile yayınlanan istatistikler derlenmiş, ayrıca sektörün önde gelen oyuncuları ve uzmanlarıla bire bir mülakatlar gerçekleştirilmiştir.

Bulgular- Araştırma ile iklimlendirme sektörünün rekabet gücü analizlerinde kullanılabilecek rekabet gücü belirleyicilerinin neler olduğu ortaya konmuştur.

Sonuç- Birincil araştırma ile elde edilen bulgular, gelecekteki araştırmalar için iklimlendirme sektörünün rekabet gücü analizine temel oluşturmuştur.

Anahtar Kelimeler: Rekabet gücünün belirleyicileri, iklimlendirme, rekabet gücü.

JEL Kodları: L64, F17 


\section{Giriş}

Rekabet gücü, göreli olarak bir sektörün diğer ülkelerin aynı sektörlerine göre daha yüksek gelir ve istihdam yaratma gücü olarak tanımlanabilir (Gürpınar ve Sandıkçı:2008). Sektörlerin uluslararası rekabet gücünün analizi sektörle ilgili tüm aktörler için büyük önem arz etmektedir. Sektörde faaliyette bulunan firmaların üretim, pazarlama ve dış ticaret stratejileri ile hedef pazar seçimleri, kamusal karar alma mekanizmalarının sektöre ilişkin politika kararları, sivil toplum kuruluşlarının faaliyet kararları ve kamu otoritelerinin teşvik kararları gibi önemli kararlar alınırken sektörün rekabet durumu göz önüne alınmaktadır.

İklimlendirme sektörü, ısıtma sistem ve elemanları, soğutma sistem ve elemanları, havalandırma-klima sistem ve elemanları ve tesisat sistem ve elemanları olmak üzere dört ana ürün grubu ile pompalar, vanalar ve yalıtım ürünleri yan ürün gruplarından oluşmaktadır (Türkiye Odalar ve Borsalar Birliği [TOBB], 2015). Orta Anadolu İklimlendirme Sanayi İhracatçıları Birliği (isiB) ve Türkiye ìhracatçılar Meclisi (TiM) verilerine göre tüm bu ürün gruplarından 2017 yılı itibarıyla 3.921.348.000 ABD \$ değerinde Türkiye'den ihracat gerçekleştirilmiş olup; küresel iklimlendirme sektörü ticaretinden Türkiye olarak alınan pay \% 0,7 düzeyindedir. Dünya ticaretinde söz sahibi olabilmeyi teminen dünya ticaretinden alınan payın çok daha yüksek oranlara çıkarılması özellikle sektörün 2023 yılı hedefi olan 20 Milyar Dolarlık ihracata ulaşması açısından önem arz etmektedir.

İhracatın bu minvalde artırılması ve rekabet gücü düzeyinin yükselmesi pozitif korelasyon içeren olgulardır. Rekabet gücü düzeyinin analiz edilerek, diğer ülkelerde veya seçilmiş pazarlardaki iklimlendirme sektörünün rekabet gücü düzeyiyle karşılaştırılması ve bu sayede sonraki dönemlerde uygulanacak stratejilerin planlanması, analizin kalitesi ve mevcut durumları en doğru şekilde yansıtmasına büyük ölçüde bağlılık göstermektedir.

\section{LITERATÜR INCELEMESI}

İklimlendirme sektörünün rekabet analizine ilişkin yazında bu yönde yapılmış çalışmanın çok sınırlı olduğu tespit edilmiştir. TOBB’un iklimlendirme sektörü raporunda bir bölüm ayrılmış ve sektörün rekabet analizi Porter’ın elmas modeli uygulanarak gerçekleştirilmiştir. Ayrıca Bulu ve diğerlerinin bilişim ve elektronik, Eraslan ve diğerlerinin plastik ve hazır giyim, Gürpınar ve Barca'nın mobilya sektörlerindeki çalışmalarında elmas modeli kullanılmıştır.

Benzer sektörlerde yapılan çalışmalar incelendiğinde ise çeşitli çalışmalarda kullanılan yöntemler araştırılmıştır. Bağcı, çalışmasında açıklanmış karşılaştırmalı üstünlükler (RCA), nispi ihracat avantajı endeksi (RXA), nispi ithalat nüfuz endeksi (RMP), nispi ticaret avantajı endeksi (RTA) ve göreli rekabet üstünlüğü endeksi (RC) endekslerini uygulamıştır (Bağcl: 2016).

Michael E.Porter, 1990 yılında yayınladığı "The Competitive Advantage of Nations" adlı kitabında ulusal rekabetin döviz kurları, faiz oranları, bütçe açıkları, cari açık vb. değişkenlerle bağdaştırılabildiğini ancak tüm bunların rekabeti tanımlamada yetersiz olduğunu farklı ülkelerde yaşanan örneklerle vurgulamaktadır. Porter, ulusal düzeyde rekabet konseptini tek bir kavrama dayandırır; verimlilik. Verimliliği ise bir birim sermaye veya işgücü tarafından üretilen çıktının değeri olarak tanımlamaktadır (Porter:1990). Verimliliğe dayalı rekabet konseptinden hareketle Porter, sektörel rekabet analizlerinde en çok kullanılan elmas modelinde ülkelerin dört niteliğinin önemine vurgu yapmaktadır.

1. Faktör Koşulları: Sektörde rekabet edebilmek için ülkenin altyapı, vasıflı işgücü vb. üretim faktörlerindeki durumu.

2. Talep Koşulları: Sektörün ürün ve hizmetleri için iç piyasadaki talebin doğası.

3. İlgili ve Destekleyici Endüstriler: Ülkede uluslararası rekabete sahip olan ilgili ve tedarikçi endüstrilerin varlığı.

4. Firma Stratejisi, Yapısı ve Rekabeti: Yurtiçi rekabet şartları ile firmaların kuruluşu, örgütlenmesi, yönetimi konularındaki şartlar.

Porter bu dört unsurun rekabetin belirleyicileri olduğunu belirtmiş ve devleti bu unsurların arasında saymamıştır. Porter'a göre devletler rekabetçi endüstri yaratamazlar, bunu sadece firmalar yapabilir. Devletin asıl rolü katalizör görevi görmek ve firmaların rekabet güçlerinin yükselmesi için arzularını yükseltmektir (Porter: 1990). Porter bu sayede devletin rolünün rekabetin belirleyicileri arasında sayılamayacağını ancak destekleyici olabileceğini belirtmektedir.

Porter çalışmasının temel prensiplerini oluştururken 10 ülkede, 100 civarında sektörde çalışma yapmıştır. Ancak son dönemde yaşanan teknolojik gelişmeler bir çok sektörde köklü değişimlerin yaşanmasına imkan sağlamıştır. Endüstri 4.0, üç boyutlu yazıcılar, nesnelerin interneti gibi çağın gelişmelerini sembolize eden konseptler ve kavramlar özellikle imalat sanayinde kendini göstermeye başlamış ve hatta akıllı evler, akıllı şehirler gibi uygulamalarla toplumsal yaşamın içerisinde bile hissedilmeye başlanmıştır. Küresel perspektifte değişim ve dönüşüm çok hızlı bir şekilde gerçekleşmekte, bazı şirketlerin 100 yıllık faaliyet ömründe ulaşabildikleri cirolara yüksek teknoloji temelli şirketler birkaç yılda ulaşabilmektedir. Porter, inovasyona dair bulgularını da kitabında belirtmiştir. Porter’a göre inovasyonu başarmak için baskı ve gereklilik gerekmektedir ve buna dair "çoğunlukla, kaybetme korkusu kazanma arzusundan güçlüdür. "demektedir (Porter:1990). Ancak çağımızda inovasyon bir gereklilik olmaktan çıkmış ve katma değer ve verimliliği sağlayan en önemli faktör haline dönüşmüştür.

Diğer taraftan Porter'ın elmas modelinde yer alan faktörlerin her sektöre ve her ülkeye uygulanabilirliği de sorgulanmaktadır. Koç ve Özbozkurt, çalışmalarında, elmas modelinin işletmelerin uluslararası başarı elde edebilmesi noktasında gereken şartları ele alırken onları kapsamlı bir biçimde incelediğini ancak firmaların uluslararası arenada başarılı olabilmelerinde bireysel çabalarının yanı sıra ulusal rekabet güçlerinin de önemli rol oynadığını bu çerçevede şirketlerin, bölgesel, küresel ve ulusal rekabet bağlamında yeni değerlendirme ölçütlerine ve rekabet araçlarına ihtiyaç duyacakları ve ulusal güç unsurlarına daha yakından bağlanacaklarını değerlendirmektedir (Koç ve Özbozkurt: 2014). 


\section{VERI VE YÖNTEM}

Yapılan araştırmanın evreni iklimlendirme sektöründe faaliyet gösteren işletmelerdir. Bu işletmelerin hepsine ulaşılması mümkün olmadığından, yargısal örnekleme yapılarak sektörün önemli aktörleri olan İklimlendirme Sanayi İhracatçıları Birliği (isiB), Isıtma Soğutma Klima Araştırma ve Eğitim Vakfı (ISKAV), İklimlendirme-Soğutma-Klima İmalatçıları Derneği (iSKiD) ve Soğutma Sanayi İşadamları Derneği (SOSIAD) seçilmiştir. Bu kuruluşların uzmanları ve başkanlarından oluşan 12 kişiyle ayrı ayrı, ISK-SODEKS fuarında derinlemesine yapılandırılmamış mülakat gerçekleştirilmiştir. Görüşmede rekabet gücü düzeyinin analizinde hangi değişkenlerin belirleyici olduğu sorusuna açıklık getirilmiştir. Elde edilen veriler betimsel analiz yöntemiyle yorumlanmış ve çıkarımlar yapılarak konu ile ilgili yazında yer alan rekabet gücü faktörleri ile karşılaştırma yapılmıştır.

\section{BULGULAR}

Yürütülen mülakatlar sonrasında elde edilen ve sınıflanan bulgulara göre, görüşme yapılan katılımcılardan iklimlendirme sektörünün rekabet gücünün analizinde alt ürün gruplarının ayrı ayrı analiz edilmesinin gerekli olduğu vurgulanarak aşağıdaki değişkenler elde edilmiştir;

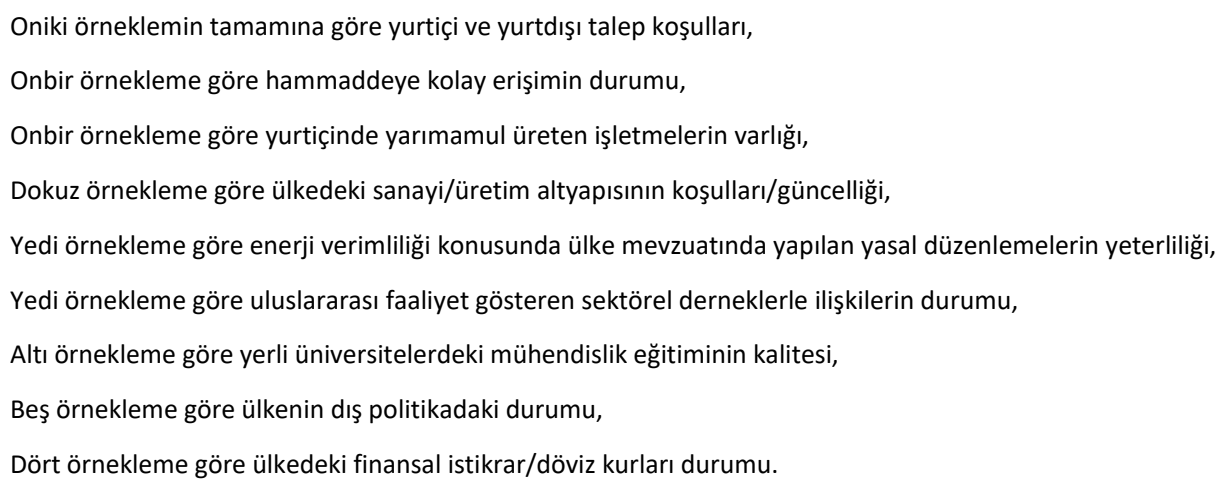

Bulgulara göre iklimlendirme sektörünün rekabet gücü düzeyinin analizinde kullanılması gerektiği ifade edilen belirleyiciler olarak talep koşulları, hammadde ile yarımamul ürüne erişim, sektörün genel üretim altyapısı, sektörle ilgili yasal düzenlemeler, Türkiye'nin özellikle döviz kurları olmak üzere finansal piyasalarındaki volatilite, Türkiye'deki mühendislik eğitimi kalitesi, Türkiye’nin dış siyasi ilişkileri ve dış ülkelerde faaliyette bulunan sektörü temsil eden STK'larla işbirliği kurabilme kabiliyeti sayılmıştır.

\section{SONUÇ}

İmalat sanayi sektörleri ve diğer sektörlerde yürütülen rekabet gücü düzeyinin belirlenmesine yönelik çalışmalar incelendiğinde ekseriyetle Porter'ın Elmas modelinin yöntem olarak tercih edildiği görülmektedir. Ancak sektörlere özel durum olup olmadığı ve bu modelin her sektöre aynı şekilde uygulanabilirliği sorgulanmamaktadır. Bu çıkış noktasından hareketle yürütülen bu çalışmada elde edilen verilerden analiz edilen bulgulara göre; talep koşulları, hammadde ile yarımamül ürüne erişim, sektörün genel üretim altyapısı, sektörle ilgili yasal düzenlemeler, Türkiye'nin özellikle döviz kurları olmak üzere finansal piyasalarındaki volatilite, Türkiye'deki mühendislik eğitimi kalitesi, Türkiye'nin dış siyasi ilişkileri ve dış ülkelerde faaliyette bulunan sektörü temsil eden STK'larla işbirliği kurabilme kabiliyeti faktörlerinin de analiz sürecine dahil edilmesi gerektiği yönünde bir eğilim olduğu çıkarımı yapılmıştır.

"Finansal piyasalardaki volatilite" faktörüne sektörün tek başına müdahale etmesi mümkün değildir veya bu konuda sektöre özel bir düzenleme yapılamamaktadır. Dolayısıyla bu faktörü sektöre özel rekabet gücünün analizinde kullanmanın uygun olacağı düşünülmemektedir.

"Mühendislik eğitiminin kalitesi" faktörüyle özellikle sektöre doğrudan işgücü sağlayabilecek makine, elektrik-elektronik, mekatronik mühendislikleri bölümü ile iklimlendirme ve soğutma bölümü öğrencilerinin eğitim müfredatında yer alan uygulamalı staj programlarının niteliğinin sektörün gelişimine uygun hale getirilmesinin önem arz ettiği ve üniversite-sanayi işbirliği programları ile firmaların da sürece dahil olabildiği ifade edilmektedir.

"Dış siyasi ilişkiler" konjonktürel bir durum olarak değerlendirilmekte ve bu konuda olumsuzluklar olması durumunda firmaların getirebileceği önlemlerin sınırlı olduğu düşünülmektedir.

“Dış ülkelerde faaliyette bulunan sektörü temsil eden STK'larla işbirliği kurabilme kabiliyeti” faktörü, sektörün yeni dış pazarlara girişi, mevcut pazarlara nüfuz, trendleri takip etmek ve mühendislikte yaşanan gelişmelere yön verebilme olanaklarını sağlaması açısından önem arz etmektedir. Yapılan mülakatlarda, sektörde yer alan yurtiçindeki sektörel sivil toplum kuruluşlarının ortak hareket kabiliyetinin avantajları vurgulanırken, yurtdışındaki küresel STK'larla ilişkilerin ve ortak hareket kabiliyetlerinin rekabet gücü düzeyine pozitif katkıları vurgulanmıştır. Örneğin American Society of Heating, Refrigerating, and Air-Conditioning Engineers (ASHRAE) ve Indian Society of Heating, Refrigerating, and Air-Conditioning Engineers (ISHRAE) gibi örgütlerle düzenlenen ortak faaliyetler ve faaliyetlere katılım sayesinde elde edilen iş yapma sinerjisinin sektöre küresel pazarda yeni fırsatlar sunduğu ve bu örgütlerde etkin olmayan ülkelere karşı rekabet üstünlüğü sağlandığı ifade edilmiştir.

Sonuç olarak, iklimlendirme sektöründe rekabet gücünün düzeyinin analizine yönelik çalışmalarda, alt ürün gruplarının (ısıtma sistem ve elemanları, soğutma sistem ve elemanları, havalandırma-klima sistem ve elemanları ve tesisat sistem ve elemanları) ayrı ayrı analiz edilmesi 
her bir alt ürün grubunun kendine has özellikleri olabileceğinden rasyonel olarak değerlendirilmektedir. Porter'ın yaygın olarak kullanılan modelinde yer alan belirleyicilerden özellikle arz ve talep unsurlarını içeren değişkenlerle bir örtüşme olduğu görülmekle beraber çalışma sonucunda, iklimlendirme sektöründe rekabet gücü düzeyinin belirleyicileri olarak talep koşulları, hammadde ile yarımamül ürüne erişim koşulları, sektörün üretim altyapısı, sektörle ilgili yasal düzenlemeler, mühendislik eğitiminin kalitesi ve dış ülkelerde faaliyette bulunan sektörü temsil eden STK'larla işbirliği kurabilme kabiliyetinin yapılacak çalışmalar kapsamında analiz edilmesinin faydalı olacağı mütalaa edilmiştir.

\section{KAYNAKLAR}

Bağcı, E. (2016). Türkiye'nin imalat sanayi sektörünün uluslararasi rekabet gücü analizi. Marmara Üniversitesi İktisadi ve İdari Bilimler Dergisi, 38(1), 73-92.

Bayraktar, Y., Kaya, H. İ. (2016). Yeni ekonomi ve değişen rekabet anlayişi: karşilaştirmali bir analiz. Bilgi Ekonomisi ve Yönetimi Dergisi, 11(1), 89-106.

Bulu, M., Eraslan, İ. H., Kaya H. (2006). Türk elektronik sektörünün rekabetçilik analizi. İstanbul Ticaret Üniversitesi Sosyal Bilimler Dergisi, 9, 49-66.

Bulu, M., Eraslan İ. H., Şahin Ö. (2004). Elmas (Diamond) Modeli İle Ankara bilişim kümelenmesi rekabet analizi. 3. Ulusal Bilgi Ekonomi ve Yönetim Kongresi, Eskişehir.

Eraslan, i. H., Bakan, İ., Kuyucu, A. D. (2008). Türk tekstil ve hazir giyim sektörünün uluslararasi rekabetçilik düzeyinin analizi. İstanbul Ticaret Üniversitesi Sosyal Bilimler Dergisi, (13), 265-300.

Eraslan, i. H., Karataş, A., Kaya, H. (2007). Türk plastik sektörünün rekabetçilik analizi. İstanbul Ticaret Üniversitesi Sosyal Bilimler Dergisi, (1), 203-219.

Gürpınar, K., Barca, M. (2007). Türk mobilya sektörünün uluslararasi rekabet gücü düzeyi ve nedenleri. Eskişehir Osmangazi Üniversitesi ïiBF Dergisi, 2(2), 47-61.

Gürpınar, K., Sandıkçı, M. (2008). Uluslararasi rekabetçilik analizinde Michael E. Porter'ın Elmas Modeli yaklaşımı: Türkiye'deki bazi endüstrilerdeki uygulanabilirliğinin ve sonuçlarinin araştırılması. Selçuk Üniversitesi Sosyal Ekonomik Araştırmalar Dergisi, 15, 105-125.

http://www.tim.org.tr/tr/ihracat-rakamlari.html (Erişim Tarihi: 21.01.2018)

Koç, M., Özbozkurt, O. B. (2014). Uluslarin rekabet üstünlüğü ve Elmas Modeli üzerine bir değerlendirme. İşletme ve İktisat Çalışmaları Dergisi, 2(3), 85-91.

Porter, M. E. (1990). The competitive advantage of nations. Harvard Business Review, April, 73-91

Porter, M. E. (2015). Rekabet stratejisi: sektör ve rakip analizi teknikleri. (Çev.Gülen Ulubilgen). İstanbul: Agora Kitaplığı. (Eserin Orijinali 1980'de yayınlandı.)

Türkiye Odalar ve Borsalar Birliği. (2015). Türkiye İklimlendirme Sektör Raporu. Ankara

www.isib.gov.tr (Erişim Tarihi: 17.12.2017). 